\title{
KEARIFAN LOKAL POMA AADUHUNUDI DESA SOAMAETEK KECAMATAN KAO BARAT KABUPATEN HALMAHERA UTARA
}

\author{
Nelci Balisosa \\ Vicky Richard Bernhard Moniaga \\ Sherly Gladys Jocom
}

\begin{tabular}{ll}
\hline Naskah diterima melalui Email agrisosioekonomi@unsrat.ac.id & : Senin, 3 Agustus 2020 \\
Disetujui diterbitkan & : Selasa, 11 Agustus 2020 \\
\hline
\end{tabular}

\begin{abstract}
This study aims to describe the local wisdom of "Poma Aaduhunu" that occurs in Soamaetek Village, Kao Barat District, North Halmahera Regency in terms of the cultural aspects of cooperation in the field of coconut farming, marriage culture, the culture of building a house or place of residence. This research was conducted from June to August 2019. Respondent was selected used purposive sampling method. This study used primary data and secondary data. Primary data were obtained from interviews, based on a list of questions that had been provided in the form of a questionnaire, with 20 household heads (KK) as respondents, who came from community members in Soamaetek Village. Secondary data were obtained from the village office and the offices of agencies related to the research. Data analysis using descriptive analysis method, the data is presented in tabular form and described descriptively. The results showed that the local wisdom of "Poma Aaduhunu" in Soamaetek Village, Kao Barat District, North Halmahera Regency is cooperation or mutual assistance which is still very strong in practice, namely in the field of coconut farming in land preparation and harvesting; the culture of the marriage at the marriage proposal ceremony ("maso minta"), making the "sabua" at the venue, preparing consumption for the wedding ceremony; house construction on land preparation and house building process. The people of Soamaetek Village still adhere to this local wisdom because they consider the local wisdom culture of "Poma Aaduhunu" to be very helpful in their daily lives." Poma Aaduhunu's" local wisdom has taken root and has become a culture inherent that has been passed down from generation to generation in the Soamaetek Village community. ${ }^{* e p r m}{ }^{*}$
\end{abstract}

Keywords: local wisdom, "Poma Aaduhunu", cultural aspects, cooperation, coconut farming, marriage and house building

\section{ABSTRAK}

Penelitian ini bertujuan untuk mendeskripsikan kearifan lokal Poma Aaduhunu yang terjadi di Desa Soamaetek, Kecamatan Kao Barat, Kabupaten Halmahera Utara di lihat dari aspek budaya kerja sama di bidang pertanian kelapa, budaya perkawinan, budaya pembangunan rumah atau tempat tinggal. Penelitian ini dilaksanakan pada bulan Juni sampai Agustus 2019. Penggambilan sampel dilakukan secara sengaja (purposive sampling). Penelitian ini menggunakan data primer dan data sekunder. Data primer di peroleh dari hasil wawancara dengan 20 Kepala Keluarga (KK) sebagai responden, yang berasal dari anggota masyarakat yang ada di Desa Soamaetek berdasarkan daftar pertanyaan yang telah di sediakan dalam bentuk kuesioner. Data sekunder di peroleh dari kantor desa dan kantor instansi-instansi yang terkait dengan penelitian. Analisis data menggunakan metode analisis deskriptif data disajikan dalam bentuk tabel dan dijelaskan secara deskriptif. Hasil penelitian menunjukkan bahwa kearifan lokal Poma Aaduhunu di Desa Soamaetek Kecamatan Kao Barat Kabupaten Halmahera Utara yaitu kerja sama atau saling membantu yang masih sangat kuat dipraktekkan yaitu di bidang pertanian kelapa pada persiapan lahan dan pemanenan; budaya perkawinan pada acara lamaran, pembuatan sabua tempat acara dilaksanakan, penyiapan konsumsi pada pelaksanaan acara perkawinan; pembangunan rumah pada persiapan lahan dan proses pembangunan rumah. Masyarakat Desa Soamaetek masih memegang teguh kearifan lokal tersebut karena mereka menggangap budaya kearifan lokal Poma Aaduhunu sangatlah membantu dalam kehidupan keseharian mereka. Kearifan lokal Poma Aaduhunu sudah mengakar, melekat dan menjadi budaya yang turun temurun dalam masyarakat Desa Soamaetek. ${ }^{* e p r m}{ }^{*}$

Kata kunci : kearifan lokal, Рота Ааduhunu, aspek budaya, kerjasama, pertanian kelapa, perkawinan dan pembangunan rumah 


\section{PENDAHULUAN}

\section{Latar Belakang}

Kearifan lokal menjadi pilar utama dalam pengelolaan kawasan bagi masyarakat lokal untuk menjaga dan melestarikan sumber daya yang ada, kebudayaan lokal berkembang dan terus di jalankan sebagai dasar bagi masyarakat untuk menjalakan kehidupannya. Kearifan lokal sering di maknai sebagai suatu pemikiran yang tidak berdasarkan pada teori-teori yang ada, yang di pahami sebagai suatu kepercayaan dan suatu tradisi yang harus dilakukan oleh masyarakat setempat. Kearifan tradisional atau kearifan lokal merupakan salah satu warisan budaya yang ada di masyarakat (tradisional) dan secara turun temurun di laksanakan oleh masyarakat yang bersangkutan. Kearifan tradisonal tersebut umumnya berisi ajaran untuk memelihara dan memanfaatkan sumberdaya alam (hutan, tanah, dan air) secara berkelanjutan (Lampe, 2006).

Desa Soamaetek berada di wilayah Kecamatan Kao Barat Kabupaten Halmahera Utara. Desa Soamaetek terdiri dari 6 RT, 3 RW dan 2 dusun dengan luas wilayah sebesar $140 \mathrm{Ha}$. Desa Soamaetek adalah desa yang di kenal dengan "Poma Aaduhuunu (saling membantu) karena masyarakat Desa Soamaetek masih memegang teguh pentingnya kearaifan lokal. Poma Aaduhunu merupakan bahasa daerah masyarakat Desa Soamaetek, yang memiliki arti saling membantu atau saling bekerja sama. Kerja sama merupakan interaksi yang sangat penting bagi kehidupan manusia karena manusia adalah mahkluk sosial yang saling membutuhkan. Perkembangan jaman yang sangat pesat dapat mengubah pola kehidupan masyarakat menjadi individualistik dan dapat menggerus budaya lokal masyarakat. Masyarakat Desa Soamaetek sebagian besar beragama kristen dan memiliki budaya kearifan lokal Poma Aaduhunudalam budaya pertanian kelapa, budaya perkawinan dan budaya pembangunan rumah. Kearifan lokal Poma Aaduhunu masih tetap terjaga dan terus dilaksanakan hingga sekarang ini.

\section{Pengertian Kearifan Lokal}

Kearifan lokal atau local wisdom merupakan gagasan-gagasan atau nilai nilai, pandangan-pandangan setempat atau (lokal) yang bersifat bijaksana, penuh kearifan, bernilai baik yang tertanam dan diikuti oleh anggota masyarakatnya. Kearifan lokal dapat diartikan nilai-nilai budaya yang baik yang ada di dalam suatu masyarakat. Hal ini berarti, untuk mengetahui suatu kearifan lokal di suatu wilayah maka kita harus bisa memahami nilai-nilai budaya yang baik yang ada di dalam wilayah tersebut. Nilai-nilai kearifan lokal ini sudah diarjarkan secara turun temurun oleh orang tua kepada anak-anaknya. (Karo, 2011).

Kearifan lokal merupakan pengetahuan eksplisit yang muncul dari periode panjang yang berevolusi bersama-sama masyarakat dan lingkungannya dalam sistem lokal yang sudah dialami bersama-sama. Proses evolusi yang begitu panjang dan melekat dalam masyarakat dapat menjadikan kearifan lokal sebagai sumber energi potensial dari sistem pengetahuan kolektif masyarakat untuk hidup bersama secara dinamis dan damai, yang bermuara pada wujud menjadi tradisi atau agama. (Tiezzi, et al, dalam Ridwan, 2007). Menurut Apriyanto (2008), kearifan lokal adalah nilai yang diciptakan, dikembangkan dan dipertahankan oleh masyarakat yang menjadi pedoman hidup mereka. Kearifan lokal adalah dapat dipahami sebagai gagasan-gagasan setempat yang bersifat bijaksana, penuh keariafan, bernilai baik yang tertanam dan diikuti oleh anggota masyarakatnya (Sartini 2004). Kearifan lokal adalah suatu bentuk pengetahuan asli dalam masyarakat yang berasal dari nilai luhur budaya masyarakat setempat untuk mengatur tatanan kehidupan masyarakat. Artinya Kearifan lokal adalah hasil dari masyarakat tertentu melalui pengalaman mereka dan belum tentu dialami oleh masyarakat lain.

\section{Bentuk Kearifan Lokal}

Nuraini Asriati dalam Wahyudi (2014) mengemukakan bahwa bentuk kearifan lokal adalah kerukunan beragam dalam wujud praktik sosial yang dilandasi suatu kearifan dari budaya. Bentuk kearifan lokal dalam masyarakat dapat berupa budaya (nilai, norma, etika, kepercayaan, adat istiadat, hukum adat, dan aturan-aturan khusus). Nilai-nilai luhur kearifan lokal meliputi : cinta kepada Tuhan, alam semesta beserta isinya; tanggung jawab, disiplin dan mandiri; jujur; hormat dan santun; kasih sayang dan peduli; percaya diri, kreatif kerja keras dan pantang menyerah; keadilan dan kepemimpinan; baik dan rendah hati; toleransi, cinta damai dan persatuan. 
Dalam karya sastra kearifan lokal merupakan bahasa, baik lisan maupun tulisan (Ratna, 2011). Dalam masyarakat kearifan lokal dapat di temui dalam cerita rakyat nyanyian, pepatah, semboyan, dan kitab-kitab kuno yang melekat dalam perilaku sehari-hari. Kearifan lokal ini akan mewujud menjadi budaya tradisi, kearifan lokal akan tercermin dalam nilai-nilai yang berlaku dalam kelompok masyarakat tertentu. Wahyudi (2014) mengemukakan kearifan lokal merupakan tata aturan tak tertulis yang menjadi acuan masyarakat yang meliputi seluruh aspek kehidupan, berupa tata aturan yang menyangkut hubungan antar sesama manusia, misalnya dalam interaksi sosial baik antar individu maupun kelompok, yang berkaitan dengan hirarkhi dalam kepemerintahan dan adat aturan perkawinan, tata karma dalam kehidupan sehari-hari.

\section{Kearifan Lokal Poma Aaduhunu}

\section{Kearifan lokal Poma Aaduhunu} merupakan bagian yang paling penting dalam kehidupan masyarakat Desa Soamaetek sejak dahulu sampai di teruskan pada generasi sekarang ini. Kearifan lokal Poma Aaduhunu sebagai tradisi atau kepercayaan yang masih dilaksanakan di Desa Soamaetek adalah dalam bidang pertanian kelapa, budaya perkawinan, dan budaya pembangunan rumah. Kearifan Poma Aaduhunu pada bidang pertanian kelapa dimulai dari pembersihan lahan. Masyarakat Desa Soamaetek melakuan pembersihan lahan atau rumput 1 tahun 3 kali pembersihan sesuai dengan kwartal dengan menggunakan alat mesin paras ada juga dengan menggunakan parang, masyarakat melakukan kerja sama dengan membentuk kelompok. Selanjutnya pada saat panen mulai dari pemanjatan pohon kelapa dan mengumpulkan buah kelapa yang biasa masyarakat Desa Soamaetek menyebut dengan sebutan para-para sampai dengan bela kore, kegiatan ini dilakukan dengan bekerja bersamasama dalam kelompok. Pada saat pasca panen biasanya mereka tidak melakukan kerja sama atau Poma Aaduhunu karena mereka melakukan pemasaran sendiri. Dibidang budaya perkawinan, diawali dengan budaya maso minta (lamaran) yang dilakukan oleh ketua- ketua adat atau dewan adat dan keluaga. Pada tahapan ini saling terjadi saling bantu antar keluarga dimana keluarga saling membantu pada saat acara maso minta dalam bentuk pengumpulan uang atau bantuan makanan. Pada saat pernikahan/perkawinan, kerjasama dalam masyarakat terjadi untuk membangun tempat pelaksanaan acara dengan membuat sabua dari bulu (bambu) dan ditutup terpal tetapi ada juga pakai tenti untuk acara perkawinan sampai selesai. Dan untuk pelaksanaan perkawinan, yang kerja sama kebanyakan ibu-ibu mereka membantu memasak sampai selesai acara tetapi juga bapak-bapak juga ikut membantu. Dibidang budaya pembangunan rumah mulai dari persiapan lahan mereka selalu saling membantu untuk membersikan lahan tempat membangun rumah. Selanjutnya proses pembangunan rumah masyarakat juga saling membantu memberikan uang dan tenaga.

\section{Rumusan Masalah}

Berdasarkan latar belakang yang di sampaikan maka menjadi rumusan masalah dalam penelitian ini adalah bagaimana kearifan lokal Poma Aaduhunu di bidang budaya pertanian kelapa, budaya perkawinan, budaya pembangunan rumah di Desa Soamaetek Kecamatan Kao Barat Kabupaten Halmahera?

\section{Tujuan Penelitian}

Tujuan penelitian adalah mendeskripsikan kearifan lokal Poma Aaduhunu yang terjadi di Desa Soamaetek Kecamatan Kao Barat di lihat dari aspek budaya kerja sama di bidang pertanian kelapa, budaya perkawinan, budaya pembangunan rumah atau tempat tinggal.

\section{Manfaat Penelitian}

Manfaat dari penelitian ini yaitu untuk :

1. Memperdalam pengetahuan bagi peneliti terkait cara berpikir sistematis serta penelitian ini merupakan salah satu syarat untuk memperoleh gelar sarjana di fakultas pertanian Universitas Sam Ratulangi Manado.

2. Bagi pemerintah dan masyarakat Desa Soamaetek untuk memberikan informasi penting tentang pentingnya kearifan lokal Poma Aaduhunu di Desa Soamaetek. 


\section{METODE PENELITIAN}

\section{Tempat dan Waktu Penelitian}

Peneltian ini di lakukan di Desa Soamatek Kecamatan Kao Barat Kabupaten Halmahera Utara. Penelitian ini di lakukan selama 3 bulan yaitu bulan Juni- Agustus 2019.

\section{Metode Pengumpulan Data}

Penelitian ini menggunakan data primer dan data sekunder. Data primer di peroleh dari hasil wawancara dengan responden, yakni masyarakat yang ada di Desa Soamaetek berdasarkan daftar pertanyaan yang telah di sediakan dalam bentuk kuesioner, sedangkan data sekunder di peroleh dari profil desa dan instansi-instansi yang terkait dengan penelitian.

\section{Metode Pengumpulan Sampel}

Pengambilan sampel dalam penelitian ini menggunakan metode pengambilan sampel purposive sampling (secara sengaja) yaitu masyarakat Desa Soamaetek yang masih memelihara dan melaksanakan kearifan local Poma Aaduhunu. baik dalam bidang pertanian kelapa, budaya perkawinan dan budaya pembangunan rumah. Sampel yang digunakan dalam penelitian ini sebanyak 20 kepala keluarga yang menjalankan kearifan lokal Poma Aaduhunu.

\section{Konsep Pengukuran Variabel}

Variabel- variabel yang di ukur dalam penelitian ini adalah sebagai berikut:

1. Kearifan lokal Poma Aaduhunu di bidang pertanian kelapa yaitu kerjasama masyarakat dalam melaksanakan kegiatan pertanian kelapa, yang meliputi:

b. Kerjasama pembersihan lahan untuk pertanian kelapa mulai dari penyiangan/pemarasan,.

c. Kerjasama pada saat panen, meliputi: kegiatan pemanjatan kelapa, pengumpulan kelapa

d. Kerjasama untuk kegiatan pasca panen: meliputi kegiatan pengolahan hasil (pemisahan daging buah dan tempurung/belah kore, pengasapan/fufu) dan kegiatan pemasaran/penjualan hasil panen.
2. Kearifan Lokal Poma Aadununudi bidang perkawinan yaitu kerjasama masyarakat dalam melaksanakan perkawinan, yang meliputi :

a. Lamaran (maso minta). Apakah ada kerjasama dalam acara lamaran (maso minta) dalam masyarakat.

b. Pembuatan tempat acara (Sabua). Apakah ada kerjasama dalam membuat bangunan tempat berlangsunnya acara yang dalam bahasa lokal disebut sebagai pembuatan Sabua.

c. Pesta Perkawinan, apakah ada kerjasama dalam masyarakat pada saat berlangsungnya pesta penikahan terutama menyangkut penyediaan konsumsi.

3. Kearifan lokal Poma Aaduhunu di bidang pembangunan rumah atau tempat tinggal adalah kerjasama yang dilakukan masyarakat pada saat keluarga atau anggota masyarakat akan melaksanakan pembangunan rumah. Kegiatan kerjasama dalam pembangunan rumah meliputi:

a. Persiapan untuk pembangunan rumah, yang meliputi kerjasama saat mempersiapkan lahan berupa pembersihan lahan untuk pembangunan rumah.

b. Proses pembangunan rumah, yaitu kerjasama/tolong menolong saat pembangunan rumah meliputi pembangunan pondasi, badan rumah dan atap rumah.

\section{Metode Analisis Data}

Penelitian ini menggunakan analisis deskriptif. Data disajikan dalam bentuk tabel dan dijelaskan secara deskriptif. Dengan menggunakan analisis deskriptif yaitu agar bisa mendeskripsikan kearifan lokal Poma Aaduhunu di bidang pertanian kelapa, bidang perkawinan, bidang pembangunan rumah di Desa Soamaetek Kecamatan Kao Barat.

\section{HASIL DAN PEMBAHASAN}

\section{Deskripsi Wilayah Penelitian}

Desa Soamaetek merupakan salah satu desa di Kecamatan Kao Barat Kabupaten Halmahera Utara. Desa Soamaetek terletak sebelah Timur dari Ibu Kota Kecamatan dengan luas wilayah sebesar140 Ha. Jarak antara desa Soamaetek dengan ibukota kabupaten/kota adalah $89 \mathrm{~km}$ dan jarak antara ibu kota kecamatan dengan Desa Soamaetek yaitu 9 KM. Desa Soamaetek terbagi dua Dusun yaitu Dusun 1 (satu) dan Dusun 2 (dua). 
Jumlah penduduk di Desa Soamaetek sebanyak 1084 jiwa (573 jiwa laki-laki dan perempuan sebanyak 511 jiwa). Sebagian besar masyarakat di Desa Soamaetek bermata pencaharian sebagai petani. Batas wilayah Desa Soamaetek adalah sebagai berikut :

Sebelah Utara : Desa Bailengit

Sebelah Selatan : Desa Soahukum

Sebelah Barat : Hutan Lindung

Sebelah Timur : Desa Toboulamo

\section{Karakteristik Responden}

\section{Umur Responden}

Umur dapat mempengaruhi cara bekerja seseorang secara fisik dan dapat menentukan cara berpikir seseorang. Usia kerja yang produktif yaitu berada pada usia 15-59 tahun. Sedangkan tenaga non produktif berada pada usia penduduk yaitu 014 tahun serta lebih atau sama dengan 60 tahun. Umur 20 orang responden di Desa Soamaetek Kecamatan Kao Barat yang menjadi sampel dalam penelitian ini, berada pada kisaran 29 - 66 tahun yang dapat dilihat pada tabel 1 .

\begin{tabular}{lcc}
\multicolumn{3}{l}{ Tabel 1. Jumlah Responden menurut Golongan Umur (Tahun) } \\
\hline $\begin{array}{l}\text { Umur responden } \\
\text { (Tahun) }\end{array}$ & Jumlah Responden (orang) & Persentase (\%) \\
\hline $29-38$ & 5 & 25 \\
$40-59$ & 13 & 65 \\
$60-66$ & 2 & 10 \\
\hline Jumlah & 20 & 100 \\
\hline
\end{tabular}

Sumber: Diolah Dari Data Primer 2019

Tabel 1 menunjukkan bahwa sebagian besar responden berada pada kisaran umur 40-59 tahun yaitu sebanyak 13 orang atau 65 persen. Responden dengan umur 60 tahun keatas sebanyak 2 orang atau 10 persen dan responden dengan kisaran umur 29-38 tahunsebanyak 5 orang atau 25 persen. Hal ini menunjukkan sebagian besar responden berada pada usia produktif.

\section{Tingkat Pendidikan}

Pendidikan merupakan faktor yang sangat penting bagi peningkatan SDM. Adanya pendidikan yang memadai dapat meningkatkan kecakapan dalam mengusahakan usahataninya sehingga dapat menguntungkan dan meningkatkan taraf hidupnya. Pendidikan berpengaruh juga terhadap kemampuan berpikir dan beradaptasi dengan lingkungannya. Tingkat pendidikan responden dapat dilihat pada Tabel 2.
Tabel 2. Tingkat Pendidikan Responden Di Desء Soamaetek Kecamatan Kao Bara Kabupaten Halmahera Utara

\begin{tabular}{lcr}
\hline $\begin{array}{l}\text { Tingkat } \\
\text { Pendidikan }\end{array}$ & $\begin{array}{c}\text { Jumlah Responden } \\
\text { (orang) }\end{array}$ & Persentase (\%) \\
\hline SD & 11 & 55 \\
SMP & 8 & 40 \\
SMA & 1 & 5 \\
\hline Jumlah & 20 & 100 \\
\hline Sumber: Diolah Dari Data Primer 2019 &
\end{tabular}

Sumber: Diolah Dari Data Primer 2019

Tabel 2 menunjukkan bahwa pendidikan responden di Desa Soamaetek berjenjang dari sekolah dasar (SD) sampai SMA. Persentase terbesar adalah berpendidikan SD, yaitu 11 orang atau 55 persen, berpendidikan SMP sebanyak 8 orang atau 40 persen, dan berpendidikan SMA sebanyak 1 orang atau 5 persen. Hal ini menunjukkan bahwa sebagian besar responden masih memiliki tingkat pendidikan yang rendah.

\section{Kearifan Lokal Poma Aaduhunu di Bidang Pertanian Kelapa}

Tanaman kelapa merupakan salah tanaman utama yang sangat menunjang kehidupan masyakat yang ada di Maluku Utara, terlebih khusus di Desa Soamaetek. Masyarakat Desa Soamaetek sebagian besar berprofesi sebagai petani kelapa. Saat melakukan usahatani kelapa (pekerjaan kelapa) membutuhkan tenaga kerja dan uang (modal) untuk memperlancar proses pekerjaan. Tingkat pendidikan yang rendah sangat berpengaruh terhadap pendapatan masyarakat, karena terbatasnya modal, maka kearifan lokal dipraktekkan oleh masyaralat Desa Soamaetek dengan cara kerja sama atau dengan istialah Poma Aaduhunu. Kearifan lokal Poma Aaduhunu yang ada di Desa Soamaetek Kecamatan Kao Barat Kabupaten Halmahera Utara biasanya mulai dari: 1) pembersihan lokasi lahan, 2) pemanjatan pohon kelapa, 3) pengumpulan buah kelapa, 4) belah kore 4 . Dengan adanya kerjasama dalam kelompok masyarakat di Desa Soamaetek yang dikenal dengan kearifan lokal Poma Аaduhunu (kerja sama) maka biaya yang di keluarkan oleh pemilik kebun kelapa tidak terlalu banyak atau besar (lebih hemat). Hal ini di lakukan sejak dahulu sampai sekarang. Dapat dilihat pada Tabel 3. 
Tabel 3. Budaya Kearifan Lokal Poma Aaduhunu di Bidang Pertanian Tanaman Kelapa Di Desa Soamaetek Kecamatan Kao Barat Kabupaten Halmahera Utara

\begin{tabular}{|c|c|c|c|c|c|c|c|}
\hline \multirow[t]{2}{*}{ No } & \multirow[t]{2}{*}{$\begin{array}{l}\text { Kearifan } \\
\text { Lokal }\end{array}$} & \multicolumn{3}{|c|}{$\begin{array}{l}\text { Jumlah Responden } \\
\text { (orang) }\end{array}$} & \multicolumn{3}{|c|}{ Persentase (\%) } \\
\hline & & $\begin{array}{l}\text { Pembersih- } \\
\text { an lahan }\end{array}$ & Panen & $\begin{array}{l}\text { Pasca } \\
\text { Panen }\end{array}$ & $\begin{array}{c}\text { Pembersihan } \\
\text { lahan }\end{array}$ & Paner & $\begin{array}{l}\text { Pasca } \\
\text { Panen }\end{array}$ \\
\hline 1 & $\begin{array}{l}\text { Kerja } \\
\text { sama }\end{array}$ & 20 & 20 & 0 & 100 & 100 & - \\
\hline 2 & $\begin{array}{l}\text { Tidak } \\
\text { bekerj } \\
\text { asama }\end{array}$ & 0 & 0 & 20 & - & - & 100 \\
\hline & Total & 20 & 20 & 20 & 100 & 100 & 100 \\
\hline
\end{tabular}

Tabel 3 menunjukkan bahwa kegiatan pembersihan lahan semua responden dalam hal ini sebanyak 20 orang atau 100 persen menyatakan mereka bekerjasama dalam proses pembersihan lahan. Pembersihan lahan biasanya dilakukan masyarakat Desa Soamaetek secara berkelompok yang terdiri dari beberapa orang. Budaya kearifan lokal Poma Aaduhunu juga dilakukan pada saat panen kelapa (pemanjatan, pengumpulan buah, dan belah kore). 100 persen responden menyatakan bahwa saat panen kelapa mereka tidak melaksanakan sendiri tapi bekerja sama dengan beberapa orang dalam kelompok sehingga mempercepat waktu panen dan dapat meringankan biaya/ongkos yang harus dikeluarkan pemilik kebun. Namun pada saat pengolahan hasil (proses belah kore dan pengasapan atau proses $f u f u$ ) dan penjualan hasil panen/pemasaran (kegiatan pasca panen) masyarakat Desa Soamaetek melalukan secara sendiri atau perorangan. Hal ini berarti bahwa kegiatan kerjasama dalam bidang pertanian hanya dilakukan pada saat pembersihan lahan dan panen sedangkan untuk pemasaran atau penjualan hasil dilakukan sendiri oleh pemilik kebun.

Pembersihan lahan selalu ada kerja sama karena membutuhkan waktu yang cukup lama dan membutukan tenaga kerja yang banyak. Apabila dilakukan dengan bekerja sama, maka penyelesaian pekerjaan akan cepat selesai. Petani Desa Soamaetek menggunakan alat/mesin paras untuk membersihkan lahan dan ada juga yang menggunakan parang untuk membersihkan kebun. Kegiatan panen juga selalu dilakukan dengan bekerja sama karena membutuhkan jumlah tenaga kerja yang cukup banyak mulai dari pemanjatan pohon kelapa dan pengumpulan buah kelapa. Masyarakat Desa Soamaetek selalu bekerja sama agar supaya proses pekerjaan cepat selesai dan tidak mengeluarkan biaya yang banyak. Kegiatan pasca panen meliputi kegiatan pengolahan hasil yang terdiri dari kegiatan pemisahan daging buah dan tempurung yang dalam bahasa lokal disebut sebagai kegiatan belah kore dan kegiatan pengasapan dalam bahasa lokal disebut sebagai kegiatan fufu serta kegiatan pemasaran/ penjualan hasil panen. Seteleh daging buah dipisahkan dari tempurung, kelapa selanjutnya diolah melalui proses pengasapan/fufu. Proses pengolahan kelapa dan pemasaran (pasca panen) biasanya dilakukan sendiri oleh pemilik kebun ke pengusaha kopra di sekitar desa. Untuk kegiatan-kegiatan yang membutuhkan tenaga kerja yang banyak Poma Aaduhunu atau kerja sama sangat membantu bagi masyarakat Desa Soamaetek karena membantu dalam meringankan ongkos produksi pembayaran tenaga kerja. Berdasarkan hasil penelitian diperoleh bahwa kearifan lokal Poma Aaduhunu di Desa Soamaetek dalam bidang pertanian kelapa yaitu tahapan pembersihan lahan panen dan panen, masyarakat masih menerapkan kerjasama dan masih dipraktekkan oleh masyarakat Desa Soamaetek hingga sekarang.

\section{Kearifan Lokal Poma Aaduhunu di Pekawinan}

Pesta perkawinan etnik masyarakat Kao (Modole) merupakan salah satu budaya tradisional bangsa Indonesia yang tetap terpelihara dibina dan dikembangkan oleh masyarakat Desa Soamaetek hingga sekarang ini. Upacara perkawinan Adat Kao sebagai bagian dari kebudayaan masyarakat di Desa Soamaetek merupakan hasil karya cipta dari nenek moyang kita yang berasal dari Kao itu sendiri dan merupakan salah satu tradisi yang hidup dan berkembang dalam masyarakat Desa Soamaetek serta memiliki makna-makna dan pesan-pesan yang sangat bernilai bagi kehidupan sosial masyarakat. Kearifan Lokal Poma Aaduhunu dalam perkawinan dapat dilihat pada Tabel 4. 


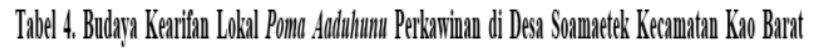
Kabopaten Halmaherra tarar

\begin{tabular}{|c|c|c|c|c|c|c|}
\hline \multirow[t]{2}{*}{ No Kearifan Lokal } & \multicolumn{3}{|c|}{ Jumlah Responden (orang) } & \multicolumn{3}{|c|}{ Persentases $(\%)$} \\
\hline & $\begin{array}{c}\text { Lamaran } \\
\text { (Maso mitata) }\end{array}$ & $\begin{array}{c}\text { Pembouatan Tempat } \\
\text { Acara (Scbuia) }\end{array}$ & $\begin{array}{l}\text { Pelakssanazan } \\
\text { Acara Perkanimana } \\
\text { (Konsumasi) }\end{array}$ & $\begin{array}{c}\text { Lamazan } \\
\text { (Yasos mixitala }\end{array}$ & $\begin{array}{l}\text { Pembuatan Tempat } \\
\text { acurar (Sabuala) }\end{array}$ & 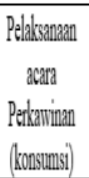 \\
\hline 1 Kerjasama & 20 & 20 & 0 & 100 & 100 & . \\
\hline 2. Tiddk Bekerassama & 0 & 0 & 20 & . & . & 100 \\
\hline Total & 20 & 20 & 20 & 100 & 100 & 100 \\
\hline
\end{tabular}

Tabel 4 menunjukkan bahwa semua responden sebanyak 20 orang (100 persen) menyatakan bahwa dalam melaksanakan acara perkawinan mereka selalu bekerjasama saling tolong menolong baik pada tahap maso minta, pembuatan Sabua untuk tempat pelaksanaan acara dan pada saat pelaksanaan acara perkawinan yaitu penyediaan konsumsi untuk acara. Budaya kerja sama atau biasa disebut Poma Aaduhunu di Desa Soamaetek dalam bidang perkawinan mulai dari lamaran (maso minta) selalu ada kerja sama dari pihak keluarga dan masyarakat. Pada umumnya acara lamaran (maso minta) dalam adat perkawinan Kao calon pengantin pria akan menyatakan niatnya menikahi calon pengantin wanita. Keluarga kedua pihak akan bertemu dan pada pertemuan ini, kedua keluarga diwakili seorang juru bicara yang akan mendiskusikan niat kedua calon mempelai untuk menikah, termasuk mendiskusikan tanggal pernikahan. Dalam adat perkawinan Kao, dalam acara lamaran (maso minta) keluarga pihak laki-laki akan menanyakan secara langsung kepada pihak keluarga perempuan berapa besar mas kawin yang di minta oleh pihak keluarga perempuan, yang dikenal dengan istilah putus suara. Untuk memenuhi permintaan dari pihak perempuan sebagai mas kawin, keluarga pihak laki-laki selanjutnya akan saling membatu melalui kearifan lokal Poma Aaduhunu. Sedangkan untuk pembuatan tempat acara juga ada kerja sama yang dimulai dari pembuatan sabua, pembuatan panggung pengantin, membantu menyiapkan kursi dan meja untuk di pakai dalam acara perkawinan dan pemasangan janur kuning untuk menghiasi bangunan tempat acara (sabua) agar terlihat lebih indah. Pada saat pelaksanaan acara kerjasama terjalin dalam bentuk penyiapan konsumsi untuk acara perkawinan. Bantuan atau kerjasama ini terjalin dalam keluarga dan anggota masyarakat lain yang bersedia untuk membantu baik dengan membantu untu memasak maupun memberikan dana untuk konsumsi.

\section{Kearifan Lokal Poma Aaduhunu di Bidang Pembangunan Rumah}

Membangun Rumah adalah hal yang pasti atau mutlak yang harus di lakukan oleh setiap orang, karena rumah adalah salah satu bangunan yang di jadikan tempat tinggal selama jangka waktu tertentu. Dalam arti khusus rumah mengacu pada konsep-konsep sosial kemasyarakatan yang terjalin di dalam bangunan tempat tinggal, seperti keluarga, hidup, makan, beraktivitas, dan lain-lain.

Membangun rumah pada saat ini, membutuh biaya yang besar karena harus mempersiapkan setiap material yang di butuhkan mulai dari lokasi, serta material untuk membangun rumah (batu, pasir, besi, semen, seng atau atap) dan biaya tukang. Dengan adanya kearifan lokal Poma Aaduhunu yang ada di Desa Soamaetek Kecamatan Kao Barat Kabupaten Halmahera Utara besarnya biaya pembangunan rumah dapat diatasi karena masyarakat akan saling bekerja sama dalam membersihkan lahan dan membantu dalam proses pembangunan rumah sehingga biaya untuk membayar tenaga kerja dapat diminimalisir. Kearifan lokal Poma Aaduhunu sampai sekarang ini masih dilakukan oleh masyarakat Desa Soamaetek maupun pendatang yang tinggal di Desa Soamaetek. Kearifan Lokal Poma Aaduhunu di Bidang Pembangunan Rumah dapat dilihat pada Tabel 5.

Tabel 5. Budaya Kearifan Lokal Di Bidang Pembangunan Rumah di Desa Soamaetek Kecamatan Kao Barat Kabupaten Halmahera Utara

\begin{tabular}{llcccc}
\hline & & \multicolumn{2}{c}{$\begin{array}{c}\text { Jumlah Responden } \\
\text { (orang) }\end{array}$} & \multicolumn{2}{c}{ Persentase $(\%)$} \\
\cline { 3 - 6 } No & $\begin{array}{l}\text { Kearifan } \\
\text { Lokal }\end{array}$ & $\begin{array}{c}\text { Persiapan } \\
\text { lahan }\end{array}$ & $\begin{array}{c}\text { Proses } \\
\text { pembagunan } \\
\text { rumah }\end{array}$ & $\begin{array}{c}\text { Persiapan } \\
\text { lahan }\end{array}$ & $\begin{array}{c}\text { Proses } \\
\text { pembagunan } \\
\text { rumah }\end{array}$ \\
\hline $\begin{array}{l}\text { 1. } \\
\text { 2. }\end{array}$ & Kerja Sama & 20 & 20 & 100 & 100 \\
& $\begin{array}{l}\text { Tidak } \\
\text { Bekerjasama }\end{array}$ & 0 & 0 & - & - \\
\hline & Total & 20 & 20 & 100 & 100 \\
\hline
\end{tabular}

Sumber: Data Primer Yang Diolah,2019. 
Tabel 5 menunjukkan bahwa 100 persen atau semua responden dalam penelitian menyatakan bahwa dalam membangun rumah mereka selalu bekerja sama baik dalam persiapan lahan maupun memberikan tenaga dalam proses pembangunan rumah. Budaya Kearifan Lokal Poma Aaduhunu di Desa Soamaetek dalam bidang pembangunan rumah sudah menjadi kebiasaan masyarakat pada umumnya dan lebih khusus juga dari pihak keluaraga berkeluarga mulai dari persiapan lahan untuk pembangunan rumah selalu ada kerja sama saling membantu membersihkan lahan untuk membangun rumah dan proses membangun rumah.

\section{KESIMPULAN DAN SARAN}

\section{Kesimpulan}

Kearifan lokal Poma Aaduhunu di Desa Soamaetek Kecamatan Kao Barat Kabupaten Halmahera Utara yaitu kerja sama atau saling membantu di bidang pertanian Kelapa, budaya Perkawinan, Pembangunan Rumah masih sangat kuat dan masyarakat Desa Soamaetek masih memegang teguh Kearifan Lokal tersebut karena mereka menggangap budaya Kearifan lokal Poma Aaduhunu sangatlah membantu dalam kehidupan keseharian masyarakat Desa Soamaetek. Kearifan lokal Poma Аaduhunu sudah mengakar dan menjadi budaya yang turun temurun melekat dalam masyarakat Desa Soamaetek.

\section{Saran}

Masyarakat Desa Soamaetek pada generasi sekarang ini yang disebut sebagai generasi milenial dapat terus mempertahankan kearifan lokal Poma Aaduhunu dan lebih meningkatkan rasa toleransi dan tolong menolong sehingga kearifan lokal Poma Aaduhunu dapat terus diterapkan dari genrasi ke genarasi.

\section{DAFTAR PUSTAKA}

Apriyanto, 2008. Hubungan Kearifan Lokal Masyarakat Adat Dengan Pelestarian Ligkungan Hidup Universitas Pendidikan Indonesia. Bandung.

Lampe 2006. Nilai Pelestarian Lingkungan Dalam Kearifan Lokal Lubuk Larangan Galau Agung Dikampung Surau Kabupaten Dharmasraya Propinsi Sumatera Barat. Prosiding Seminar Nasional Pengelolaan Sumberdaya Alam Dan Lingkungan.

Ratna, Nyoman Kutha, 2011. Antropologi Sastra: Peranan Unsur-Unsur Kebudayaan Dalam Proses Kreatif. Yogyakarta: Pustaka Pelajar.

Ridwan, A. 2007. Landasan Keilmuan Kearifan Lokal Ibda" Vol. 5 No. 1 JanJun 200 P.2-38.

Sartini. 2004. Mengenali Kearifan Lokal Nusantra: Sebuah Kajian Filsafati.

Wahyudi Agung. 2014 "Implementasi Sekolah Berbasis Kearifan Lokal di SD Negeri Sendangsari Pajangan" Skripsi Universitas Negeri Yogyakarta. 